\title{
Mass Transfer Studies in Shallow Bubble Column Reactors
}

\author{
Raymond Lau ${ }^{1,1}$, Pei Hui Venus Lee ${ }^{1}$, and Tao Chen ${ }^{2}$
}

1. School of Chemical and Biomedical Engineering (SCBE), Nanyang Technological University (NTU), 62 Nanyang Drive, Singapore 637459

2. Division of Civil, Chemical and Environmental Engineering, University of Surrey, Guildford GU2 7XH, UK

\begin{abstract}
Mass transfer studies are carried out in a bubble column with an internal diameter of 14 $\mathrm{cm}$ and various static liquid heights. The mass transfer coefficient is evaluated by using an oxygen sorption method. A model considering the gas holdup flushing and the sensor response is used. The interfacial mass transfer area is determined according to the measured bubble size distribution. The liquid-side mass transfer coefficient is also estimated from the volumetric mass transfer coefficient and the interfacial mass transfer area found. Results show that the effect of static liquid height on gas-liquid mass transfer is primarily on the interfacial mass transfer area. The mass transfer process is also governed by the type of gas distributor used. A single nozzle distributor is not suitable for shallow bubble column operations due to the large initial bubbles and the large volume of dead zone generated. It is also found that the different dependence of the liquid-side mass transfer coefficient on the superficial gas velocity observed in the literatures is due to the different bubble rising regimes.
\end{abstract}

Keywords: Gas-liquid mass transfer, bubble columns, bubble, hydrodynamics, gas holdup, shallow bed

\footnotetext{
${ }^{1}$ Corresponding author. Tel.: +65 63168830; fax: +65 67947553

Email address: wmlau@ntu.edu.sg (R. Lau).
} 


\section{Introduction}

Bubble column reactors have wide range of industrial applications because of the simple design and excellent heat and mass transfer properties. Most traditional design of bubble column reactors favors a high height-to-diameter ratio (L/D) to allow system hydrodynamics to reach a fully developed state [1-5]. The gas distributor region is generally ignored in the scale-up considerations. However, a reduction in the L/D ratio can lower the bed pressure drop and fully utilize the high gas holdup resulting from the small bubbles generated in the distributor region. In fact, the shallow bed concept has been applied in many gas-solid operations [6-11], in which the bubbling processes in fluidized gas-solid mixtures are analogous to bubble column operations. Therefore, it is beneficial to explore the feasibility bubble column reactor operations with a low L/D ratio.

There is limited study available on shallow bed reactors. Most of the studies available focus on the effect of gas distributor design on the performance of shallow bubble column [3, 1216]. However, there are mixed reports on the effect of static liquid height on bubble column performance. Gopal and Sharma [12] found that L/D ratio, column diameter and distributor design have no significant effect on gas holdup, interfacial mass transfer area, and liquid-side mass transfer coefficient in low L/D bubble columns. Kumar et al. [1] also found no effect of the static liquid height on the overall gas holdup while the local gas holdup increases with the axial distance from the distributor. Other researchers found a decrease in gas holdup with an increase in static liquid height $[4,17,18]$.

This study focuses on the mass transfer behavior in a bubble column with shallow liquid heights. Overall gas holdup $\left(\varepsilon_{G}\right)$, bubble size distribution and volumetric gas-liquid mass transfer coefficient $\left(k_{L} a\right)$ are measured under various conditions. The mass transfer behavior is 
investigated in terms of interfacial mass transfer area $(a)$ and liquid-side mass transfer coefficient $\left(k_{L}\right)$. Parameters such as superficial gas velocity $\left(U_{G}\right)$, liquid bed height to column diameter ratio (L/D), and gas distributor types are varied.

\section{Experimental}

\subsection{Setup}

The schematic of the experimental setup is shown in Figure 1. The column is made of acrylic with a height of $150 \mathrm{~cm}$ and an internal diameter of $14 \mathrm{~cm}$. Three types of gas distributors, namely, perforated plate, porous plate and single nozzle distributors are used. Perforated plate and porous plate distributors are two the most commonly used distributors in bubble column operations and single nozzle distributor can be considered as an extreme configuration of perforated plate (multi-nozzle) distributor. The perforated plate distributor has 211 orifices. The orifices have a diameter of $3 \mathrm{~mm}$ configured in a triangular pitch pattern in a pitch distance of $9 \mathrm{~mm}$. The porous plate distributor is made of nickel-chromium alloy with a thickness of $2 \mathrm{~mm}$ and a mean pore diameter of $0.6 \mathrm{~mm}$. The single nozzle distributor has a 5.5 $\mathrm{mm}$ diameter orifice located at the center of the distributor plate. The static liquid height is varied from L/D of 2 to 7.2. Tap water is used as the liquid phase while both air and nitrogen are used as the gas phase. The superficial gas velocity is varied from $3.2 \mathrm{~cm} / \mathrm{s}$ to $10.8 \mathrm{~cm} / \mathrm{s}$. All the experiments are performed at a temperature of $25^{\circ} \mathrm{C}$ and atmospheric pressure. A list of the experimental conditions including the gas distributors and L/Ds used together with the respectively $U_{G}$ range is shown in Table 1. 
The gas-liquid mass transfer coefficient is measured by using a dynamic oxygen absorption method with a discontinuous switch from nitrogen to air. The oxygen concentration in the liquid phase is monitored by an optical fiber oxygen probe. The probe tip is coated with a dye that emits $600 \mathrm{~nm}$ fluorescence when it is excited by a $470 \mathrm{~nm}$ light source. The intensity of the fluorescence, measured by a spectrometer, is linearly proportional to the dissolved oxygen concentration in the liquid phase. A two-point calibration of the optical fiber oxygen probe is done by purging water with nitrogen and with air. The optical fiber oxygen probe is placed at 28 $\mathrm{cm}(\mathrm{L} / \mathrm{D}=2)$ above the distributor plate at the center of the column. For the absorption process, nitrogen is used to purge all the dissolved oxygen from water. When the dissolved oxygen concentration reaches zero, the nitrogen flow is stopped and immediately switched over to a preset air flow. The dissolved oxygen concentration is monitored throughout the process until it reaches a saturated steady state value.

The bubble size is measured by using a high speed camera (i-Speed, Olympus, Tokyo, Japan) to capture the bubble images at various heights of the column at a frame rate of $600 \mathrm{~Hz}$. As air bubbles in water tend of have elliptical shapes, the maximum dimensions of the elliptical bubbles are taken as the bubble size. A scale of $10 \mathrm{~mm}$ in length is placed on the inner surface of the bubble column to act as the reference scale for bubble size determination. The focus of the camera is set at $5 \mathrm{~cm}$ behind the column wall. Only in-focused bubble sizes are measured to prevent the inclusion of bubbles at the wall. The size measurement method has been verified with 15 spherical particles settling inside the bubble column and the average error is found to be less than $4.4 \%$. For each operating condition, a minimum population size of 200 is used. The overall gas holdup is determined by using the bed expansion method. 


\subsection{Determination of $k_{L} a$}

Assuming that the liquid is perfectly mixed and there are negligible changes in the oxygen concentration in the gas bubbles, the oxygen sorption process can be described by the following ordinary different equation (ODE):

$$
\frac{d C_{L}}{d t}=\frac{k_{L} a}{\varepsilon_{L}}\left(\frac{C_{G}}{H}-C_{L}\right)
$$

where $C_{L}$ is the oxygen concentration in the liquid phase, $C_{G}$ is oxygen concentration in the gas phase and $H$ is the Henry's Law constant. By solving Eq.(1) the expression of oxygen concentration in the liquid phase at various times can be obtained:

$$
\frac{H C_{L}}{C_{G}}=1-e^{-\frac{k_{L} a}{\varepsilon_{L}} t}
$$

where the initial oxygen concentration in the liquid phase is assumed to be zero (i.e. $\left.C_{L}(0)=0\right)$. However, at the discontinuous switch from nitrogen to oxygen, the gas bubbles in the bubble column is occupied by nitrogen $[19,20]$ and Eq. (1) does not consider the flushing process of the existing nitrogen gas bubbles with air bubbles in the system. To account for the flushing process, the gas phase can be considered in plug flow from the gas distributor and the liquid phase is well-mixed. The mass transfer in the gas phase can be described by the partial differential equation (PDE) as [20]:

$$
\frac{d C_{G}}{d t}=-\frac{U_{G}}{\varepsilon_{G}} \frac{\partial C_{G}}{\partial z}-\frac{k_{L} a}{\varepsilon_{G}}\left(\frac{C_{G}}{H}-C_{L}\right)
$$

In addition, the oxygen sensor has slight delay in measuring the oxygen concentration and this delay will also need to be considered. The relationship between the actual oxygen concentration in the liquid phase and the oxygen concentration measured by the sensor can be described by: 


$$
\frac{d C_{\text {sensor }}}{d t}=k_{\text {sensor }}\left(C_{L}-C_{\text {sensor }}\right)
$$

where $k_{\text {sensor }}$ is the time constant of the sensor and $C_{\text {sensor }}$ is the measured oxygen concentration. Since the height of the bed is shallow, the effect of dispersion can be neglected.

To solve the model including Eqs. (1), (3) and (4), the PDE (Eq. (3)) is first discretized in the one-dimensional space coordinate $(z)$ into a set of ODEs using the method of lines. Subsequently, these ODEs are combined with Eqs. (1) and (4) and solved to obtain the time trajectory of $C_{L}, C_{G}$ and $C_{\text {sensor }}$. Based on the solver, the optimal model parameters, $k_{L} a$ and $k_{\text {sensor, }}$ are determined by minimizing the least-squares fitting errors between the model prediction and the oxygen concentration measured by the sensor. The model solver and the nonlinear least-squares optimization problem are implemented in Matlab.

\subsection{Determination of $k_{L}$ and a}

It is found that the bubble size distribution obtained can be described by a log-normal distribution. The log-normal distribution function can be expressed by:

$$
f_{N}(b)=\frac{1}{\sqrt{2 \pi} b \beta} \exp \left[-\frac{(\ln b-\alpha)^{2}}{2 \beta^{2}}\right]
$$

The mean and variance of the bubble size can be determined by:

$$
\begin{aligned}
& \mu=\exp \left(\alpha+\frac{\beta^{2}}{2}\right) \\
& \sigma^{2}=\exp \left(2 \alpha+\beta^{2}\right)\left[\exp \left(\beta^{2}\right)-1\right]
\end{aligned}
$$

$\alpha$ and $\beta$ are determined by fitting Eq.(5) to the experimentally determined bubble size distribution using the least-squares method. The bubbles in an air-water system appear in a wide variety of shape. Based on experimental observation, it is assumed that all the bubbles have an 
oblate spheroidal shape with an average major to minor axis ratio of 3 . The volume and surface area of an oblate spheroid can be determined by the equations:

$$
V=\frac{1}{6} \pi x^{2} y
$$

and

$$
A=\frac{1}{2} \pi\left(x^{2}+\frac{y^{2}}{\sin \left[\cos ^{-1}\left(\frac{y}{x}\right)\right]} \ln \left\{\frac{1+\sin \left[\cos ^{-1}\left(\frac{y}{x}\right)\right]}{\frac{y}{x}}\right\}\right)
$$

respectively, where $x$ is the length of the major axis and $y$ is the length of the minor axis of the oblate spheroid. Therefore, for the observed average major to minor axis ratio of $3, b=x=3 y$. The volume of the bubbles can then be expressed as a function of the major axis only:

$$
V=\frac{1}{18} \pi b^{3}
$$

while the surface area of the bubbles as a function of major axis can be expressed as:

$$
A=\pi b^{2}\left(1+\frac{1}{9} \frac{\ln \left\{3\left(1+\sin \left[\cos ^{-1}\left(\frac{1}{3}\right)\right]\right)\right\}}{\sin \left[\cos ^{-1}\left(\frac{1}{3}\right)\right]}\right)=1.208 \pi b^{2}
$$

The interfacial mass transfer area, $a$, is defined as the ratio of total gas-liquid interfacial area to the volume of liquid in the reactor,

$$
a=\frac{\int_{0}^{\infty} f_{N}(b)\left(1.208 \pi b^{2}\right) d b}{\frac{\left(1-\varepsilon_{G}\right)}{\varepsilon_{G}} \int_{0}^{\infty} f_{N}(b)\left(\frac{1}{18} \pi b^{3}\right) d b}
$$


Substitute Eq (5) into Eq (8) and carry out the integration, $a$ can then be obtained if $\alpha$ and $\beta$ are known:

$$
a=\frac{18(1.208) \varepsilon_{G}}{\left(1-\varepsilon_{G}\right) \exp \left(\alpha-\frac{5}{2} \beta^{2}\right)}
$$

With the interfacial mass transfer area being determined, $k_{L}$ can then be decoupled from $k_{L} a$.

\section{Results and discussion}

\subsection{Comparison of $k_{L}$ a determination with and without the consideration of the sensor delay}

A sample comparison of experimental data with and without considering the gas holdup flushing and sensor delay is shown in Figure 2. As shown in the figure, a much better fit to the experimental data can be done by taking into consideration both the gas holdup flushing and the sensor delay. A sample comparison of the $k_{L} a$ values determined with or without considering the sensor delay and the flushing of gas holdup is shown in Figure 3. It can be seen that there is a negligible difference to the $k_{L} a$ values at low $U_{G}$. This is because the mass transfer process is slow and the gas holdup is small at low $U_{G}$. The sensor will have enough time to reflect the actual oxygen concentration in the liquid phase. As $U_{G}$ is increased to about $11 \mathrm{~cm} / \mathrm{s}$, the difference between the $k_{L} a$ values determined with or without considering the gas holdup flushing and sensor delay becomes larger. It is important to include the gas holdup flushing and sensor delay at the evaluation of the experimental data for more accurate determination of $k_{L} a$ particularly at high $U_{G}$. 


\subsection{Comparison to literature data}

Additional verification of the experimental results is performed by comparing the experimental result in the current study to literature data under similar air-water systems [19, 2128]. Since there is limited literature data available for low $L / D$ ratio conditions, only experimental results obtained at L/D ratio of 7.2 are used for comparison. It can be seen in Figure 4 that there is large deviation in mass transfer coefficient as well as gas holdup among the literature even for simple air-water system. The large deviation is partially due to the different gas distributors used, impurities present in the water or even a variation in the experimental temperatures among the literature studies. In particular, the $k_{L} a$ and $\varepsilon_{G}$ reported in Kojima et al. [23] are the lowest among the literature data due to the use of single nozzle distributor. It is found that the gas distributor design can affect $\varepsilon_{G}$ significantly $[15,19]$ while a difference of a few Celsius is sufficient to cause a substantial change in the $k_{L} a$ of the system [24]. Nonetheless, both $k_{L} a$ and $\varepsilon_{G}$ obtained in the current study is comparable to literature reported results.

\subsection{Effect of static liquid height}

The gas holdup of the bed operated with the perforated plate distributor is determined with various static liquid heights expressed in L/D ratios and the result is shown in Figure 5. It can be seen that the gas holdup decreases with an increase of L/D ratio from 2 to 7.2. The small bubbles generated at the distributor are the main contributor to the higher gas holdup due to the large residence time of the slowly rising small bubbles. As the L/D ratio is increased, there is a longer travel distance for the small bubbles to continue rising through the liquid phase. Depending on the bubble concentration, bubble coalescences may occur and cause a reduction in the gas holdup as observed in the experiments. Eventually, the rates of bubble breakup and 
coalescence reach equilibrium and the gas holdup is completely governed by the dynamics of the bubble-bubble interactions. Thus, it is beneficial to keep a shallow bed height to fully utilize the high gas holdup region near the gas distributor.

The volumetric mass transfer, $k_{L} a$, for various static liquid heights is shown in Figure 6 . The measured $k_{L} a$ values correlate well with the gas holdup results that an increase in L/D ratio reduces the $k_{L} a$. It is believed that the effect of $\mathrm{L} / \mathrm{D}$ ratio on $k_{L} a$ is more than just the difference in the gas holdup, but also the bubble dynamics and mixing between the gas and the liquid phases. The gas holdup is a combined representation of the bubble concentration and the bubble rise velocities. The gas holdup itself can only provide qualitative information on the mass transfer interfacial area. In fact, $k_{L} a$ consists of two separate terms, the liquid-side mass transfer coefficient, $k_{L}$, and the interfacial mass transfer area, $a$. A more detailed analysis is needed to assess the two terms separately. The $a$ value can be determined by Eq.(13) assuming that all the bubbles have an oblate spheroidal shape and an average major to minor axis ratio of 3 . The bubble size distributions are measured at the same operating conditions as the $k_{L} a$ measurements and are assumed to follow a log-normal distribution. Figure 7 shows the effect of L/D ratio on $a$. It can be seen that an L/D of 2 gives the highest $a$ while the $a$ for $\mathrm{L} / \mathrm{D}$ of $4,5.6$ and 7.2 are comparable. The difference in $a$ among the various static liquid height is more apparent at large $U_{G}$. An increase in $U_{G}$ directly affects the bubble concentration in the system. In this case, the presence of axial distance for the bubbles to interact is of utmost importance to the overall bubble dynamics, which in turn affects the interfacial mass transfer area of the system. The $k_{L}$ value can be determined by dividing the obtained $k_{L} a$ with $a$ and the result is shown in Figure 8 . The $k_{L}$ values are found to be fairly independent of both $\mathrm{L} / \mathrm{D}$ and $U_{G}$ though some variations can be observed. Since the orifice size of the perforated plate is large, low pressure drop across the 
distributor is present. The bubble formation process can generate substantial pressure fluctuation in the plenum $[5,29]$. The variation in $k_{L}$ is likely due to the uneven distribution of bubbles caused by the substantial pressure fluctuation at the plenum.

\subsection{Effect of distributors}

For shallow bed operations, the mass transfer is extremely sensitive to the gas distributor design since the gas distributor governs the initial bubble size and the shallow bed height inhibits extensive bubble-bubble interactions. Three types of distributors are used in this study, namely the single nozzle, perforated plate and porous plate distributors. Though a low bed height allows a high gas holdup and a high $k_{L} a$, a small L/D is more susceptible to foaming problem at the liquid surface. Thus, the effect of the gas distributor is studied at a L/D ratio of 4 . The effect of the gas distributor on the gas holdup is shown in Figure 9. It can be seen that the single nozzle distributor gives the lowest gas holdup while the perforated plate and porous plate distributor yield similar gas holdups at all superficial gas velocities. A more detailed interpretation can be obtained based on the bubble size distributions of the three distributors shown in Figure 10. It can seen from Figure 10(c) that the single nozzle distributor generates extremely large initial bubbles due to the relatively large orifice size used. As gas velocity is increased, the shearinduced bubble breakup allows the single nozzle distributor to generate smaller bubbles than that at low gas velocities. At a gas velocity of $8.7 \mathrm{~cm} / \mathrm{s}$, the bubble size distribution generated at the single nozzle distributor is approaching those generated at the perforated plate and the porous plate distributors though there is still a clear difference among the bubble size distributions. It is also noted that the single orifice forms an inverted conical shape bubble jet during bubble generation. A large dead zone volume is present under this bubble jet at the bottom of the bubble 
column, and further deteriorates the performance of the single nozzle distributor. For these reasons, a lower gas holdup is observed with the single nozzle distributor compared to the perforated plate and the porous plate distributors.

The effect of gas distributor on the volumetric mass transfer coefficient can be seen in Figure 11. The $k_{L} a$ for the single nozzle distributor is the lowest among the three gas distributors while the porous plate distributor is found to give the highest $k_{L} a$. As expected for operations with shallow liquid height, there is insufficient axial distance for extensive bubble-bubble interactions. Essentially, the bubble column performance is completely governed by the initial bubble size. The interfacial mass transfer area for each distributor type can be found in Figure 12. It is to note that $a$ is governed by a combined effect of bubble size distribution as well as the gas holdup in the bubble column. Small bubbles in general have small bubble rise velocities and hence long residence time to give rise to high gas holdup. However, the low pressure wake regions large rising bubbles can cause small bubbles in the wake regions to rise at similar velocities of the large bubbles. The extent of the bubble-bubble interactions depends on the bubble concentrations which relates to the bubble size distribution as well as the gas flow rate. Therefore, the wide bubble size distribution generated at the single nozzle distributor gives rise to a considerably lower $a$ than both the perforated plate distributor and the porous plate distributor. As shown in Figure 13, $k_{L}$ of single nozzle turns out to be the highest among the three gas distributors. This is coherent with the penetration theory that large bubbles will give rise to a shorter contact time between the gas and liquid phases, hence a higher $k_{L}$ [30]. As $U_{G}$ increases, the large bubbles formed at the single nozzle are sheared into smaller bubbles and the effect of the short contact time is diminishing. It is also noted that $k_{L}$ for perforated and porous plate is found to be essentially constant within the whole $U_{G}$ range in this study. A comparison of the 
mass transfer study results in the literature indicates that there are mixed results reported regarding the dependence of $k_{L}$ on $U_{G}$. Some researchers found $k_{L}$ to be independent of $U_{G}$ [3134]. Gopal and Sharma [35] found $k_{L}$ to decrease slightly with $U_{G}$ [12] while Lemoine et al. [35] and Mena et al. [36] found $k_{L}$ to increase with $U_{G}$. Han and Al-Dahhan [19] found that $k_{L}$ increases with $U_{G}$ at low $U_{G}$ range but the increase in $k_{L}$ is not significant at high $U_{G}$ range. A summary of the conditions of the studies and their respectively bubble rise Reynolds number is shown in Table 2. The bubble rise Reynolds number, $\mathrm{Re}_{\mathrm{b}}$ is defined as:

$$
\operatorname{Re}_{\mathrm{b}}=\frac{\rho_{L} u_{b} d_{b}}{\mu_{L}}
$$

where $\rho_{L}$ is the liquid density, $\mu_{L}$ is the liquid viscosity, $u_{b}$ is the bubble rise velocity and $d_{b}$ is the bubble diameter. The maximum $\mathrm{Re}_{\mathrm{b}}$ is estimated according to the size and rise velocity of the largest bubbles together with the fluid properties reported in the studies while the minimum $\operatorname{Re}_{\mathrm{b}}$ is estimated according to the smallest bubble size and rise velocity reported. Interestingly, it can be seen from the table that the two studies that reported an increasing trend of $k_{L}$ with $U_{G}$ have a lower range of the $\mathrm{Re}_{\mathrm{b}}$. For the bubble rising behavior of an isolated spherical bubble, $\mathrm{Re}_{\mathrm{b}}$ of $2-$ 500 can be considered to be in intermediate regime where $u_{b} \propto d_{b}^{1.14} . \operatorname{Re}_{\mathrm{b}}$ of $500-56000$ would correspond to the bubble rising in the Newton regime where $u_{b} \propto d_{b}^{0.5}$. The penetration theory states that $k_{L}$ is proportional to the square root of the contact time [30]. $k_{L}$ can be related to $d_{b}$ based on the relationship between the contact time and bubble rising regime:

$$
\begin{array}{ll}
k_{L} \propto d_{b}^{0.57} & \text { for } 2<\operatorname{Re}_{\mathrm{b}}<500 \\
k_{L} \propto d_{b}^{0.25} & \text { for } 500<\operatorname{Re}_{\mathrm{b}}<200000
\end{array}
$$

It is generally accepted that the $d_{b}$ increases slightly with $U_{G}$. Krishna et al. [37] proposed a correlation that $d_{b}$ increases with $U_{G}^{0.376} . k_{L}$ is a very weak function of $U_{G}$ at high $\mathrm{Re}_{\mathrm{b}}$. Therefore, 
$k_{L}$ is observed to be independent of $U_{G}$ at high $\operatorname{Re}_{\mathrm{b}}$ and increases with $U_{G}$ at low $\operatorname{Re}_{\mathrm{b}}$ in various studies. Though the analysis is for isolated spherical bubble, the dependence is believed to be valid for multiple bubble rise conditions where bubble-bubble interactions and deformation of bubble boundaries are present.

\section{Concluding Remarks}

The volumetric gas-liquid mass transfer coefficient is determined using the oxygen sorption method in an air-water bubble column with shallow liquid heights. A consideration of the gas holdup flushing and sensor delay is needed due to the relatively short mass transfer process. The liquid-side mass transfer coefficient and interfacial mass transfer area are decoupled by considering the bubbles have an oblate spheroidal shape and an average major to minor axis ratio of 3. Results show that the effect of the static liquid height on the mass transfer is primarily on the interfacial mass transfer area. A shallow liquid height suppresses bubble coalescence and breakup and results in a higher interfacial mass transfer area than a deep liquid height. The mass transfer process is also governed by the type of gas distributor used. The perforated plate and porous plate distributors show similar behavior while the single nozzle distributor yields significantly lower performance. Due to the large initial bubbles and the large volume of dead zone generated by the single nozzle distributor, the use of single nozzle distributor in the shallow bed operation should be avoided. A theoretical analysis of the bubble rising behavior indicates that the various dependence of liquid-side mass transfer coefficient on the superficial gas velocity observed in the literatures is governed by the bubble rising regimes. 


\section{Nomenclature}

$a$

A

b

$C_{G}$

$C_{L}$

$C_{\text {sensor }}$

$d_{b}$

D

$f_{N}$

$H$

$k_{L}$

$k_{\text {sensor }}$

$\mathrm{L}$

$\operatorname{Re}_{\mathrm{b}}$

$t$

$u_{b}$

$U_{G}$

V

$x$

$y$

$z$
Interfacial mass transfer area per unit dispersion volume, $\mathrm{m}^{2} / \mathrm{m}^{3}$

Surface area, $\mathrm{m}^{2}$

Variable for bubble size, $\mathrm{m}$

Oxygen concentration in the gas phase, $\mathrm{mol} / \mathrm{m}^{3}$

Oxygen concentration in the liquid phase, $\mathrm{mol} / \mathrm{m}^{3}$

Oxygen concentration measured by oxygen sensor, $\mathrm{mol} / \mathrm{m}^{3}$

Bubble diameter, $\mathrm{m}$

Column diameter, $\mathrm{m}$

Number density function, dimensionless

Henry's Law constant, dimensionless

Liquid-side mass transfer coefficient, $\mathrm{m} / \mathrm{s}$

Sensor delay constant, $\mathrm{m} / \mathrm{s}$

Static liquid height, $\mathrm{m}$

Bubble Reynolds number, dimensionless

Time, s

Bubble rise velocity, $\mathrm{m} / \mathrm{s}$

Superficial gas velocity, $\mathrm{m} / \mathrm{s}$

Volume, $\mathrm{m}^{3}$

Dimension of major axis of oblate spheroid, $\mathrm{m}$

Dimension of minor axis of oblate spheroid, $\mathrm{m}$

Liquid height, $\mathrm{m}$ 


\section{Greek symbols}

$\begin{array}{ll}\alpha & \text { Variable used in log-normal distribution } \\ \beta & \text { Variable used in log-normal distribution } \\ \varepsilon_{G} & \text { Gas holdup, dimensionless } \\ \varepsilon_{L} & \text { Gas holdup, dimensionless } \\ \mu & \text { Liquid viscosity, Pa-s } \\ \mu_{L} & \text { Liquid density, } \mathrm{kg} / \mathrm{m}^{3} \\ \rho_{L} & \text { Variance, } \mathrm{m}^{2}\end{array}$

\section{Acknowledgements}

Support by AcRF Tier1 grant RG41/06 is gratefully acknowledged. 


\section{References}

[1] S.B. Kumar, D. Moslemian, M.P. Duducovic, Gas-holdup measurements in bubble columns using computed tomography, AIChE Journal, 43 (1997) 1414-25.

[2] U. Parasu Veera, J.B. Joshi, Measurement of gas holdup profile by gamma ray tomography: Effect of sparger design and height of dispersion in bubble column, Transaction of Institution of Chemical Engineering, 77 (1999) 303.

[3] B.N. Thorat, A.V. Shevade, K.N. Bhilegaonkar, R.H. Aglawe, U. Parasu Veera, S.S. Thakre, A.B. Pandit, S.B. Sawant, J.B. Joshi, Effect of sparger design and height to diameter ratio on fractional gas hold-up in bubble columns, Transaction of Institution of Chemical Engineering, 76 (1998) 823-34.

[4] P.M. Wilkinson, A.P. Spek, L.L.v. Dierendonck, Design parameters estimation for scale-up of high-pressure bubble columns, AIChE Journal, 38 (1992) 544-54.

[5] G.Q. Yang, X. Luo, R. Lau, L.-S. Fan, Bubble formation in high-pressure liquid-solid suspensions with plenum pressure fluctuation, AIChE Journal, 46 (2000) 2162-74.

[6] J. Broughton, in: J.R. Howard (ed.) Fluidized Beds: Combustion and Applications, Applied Science Publishers, New York, 1983, pp. 305-20.

[7] R.K. Chakraborty, J.R. Howard, in: J.R. Grace, J.M. Matsen (eds.) Fluidization, Plenum Press, New York, 1980, pp. 167-73.

[8] D. Harrison, J.R. Grace, in: J.F. Davidson, K. Harrison (eds.) Fluidization, Academic Press, New York, 1971, pp. 599-626.

[9] M.J. Virr, H.W. Williams, Heat Recovery by Shallow Fluidized Beds, Chemical Engineering Progress, 81 (1985) 50-56. 
[10] Z. Yan, J.Z. Yao, W.L. Wang, S.J. Liu, M. Kwauk, in: D. Kunii, R. Toei (eds.) Fluidization $I V$, Engineering Foundation, New York, 1984, pp. 607-14.

[11] J.-Y. Yang, Y.A. Liu, A.M. Squires, Pressure Drop Across Shallow Fluidized Beds: Theory and Experiment, Powder Technology, 53 (1987) 79-89.

[12] J.S. Gopal, M.M. Sharma, Mass transfer characteristics of low H/D bubble columns, Canadian Journal of Chemical Engineering, 61 (1983) 517-26.

[13] M.W. Haque, K.D.P. Nigam, J.B. Joshi, Optimum gas sparger design for bubble columns with a low height to diameter ratio, Chemical Engineering Journal, 33 (1986) 63.

[14] R. Lau, R.J. Mo, W.S.B. Sim, Bubble Characteristics in Shallow Bubble Column Reactors, Chemical Engineering Research and Design, 82 (2010) 197-203.

[15] R. Lau, W.S.B. Sim, R.J. Mo, Effect of Gas Distributor on Hydrodynamics in Shallow Bubble Column Reactors, Canadian Journal of Chemical Engineering, 87 (2009) 847-54.

[16] V.V. Ranade, Y. Tayalia, Modelling of fluid dynamics and mixing in shallow column reactors: influence of sparger design, Chemical Engineering Science, 56 (2001) 1667.

[17] M.C. Ruzicka, J. Drahos, M. Fialova, N.H. Thomas, Effect of bubble column dimensions on flow regime transition, Chemical Engineering Science, 56 (2001) 6117-24.

[18] F. Yamashita, Effect of clear liquid height and gas inlet height on gas holdup in a bubble column, Journal of Chemical Engineering of Japan, 31 (1998) 285-88.

[19] L. Han, M.H. Al-Dahhan, Gas-liquid mass transfer in a high pressure bubble column reactor with different sparger designs, Chemical Engineering Science, 62 (2007) 131.

[20] C.O. Vandu, J. Ellenberger, R. Krishna, Hydrodynamics and mass transfer in an upflow monolith loop reactor, Chemical Engineering and Processing: Process Intensification, 44 (2005) 363-74. 
[21] W.D. Deckwer, K. Nguyen-Tien, B.G. Kelkar, Y.T. Shah, Applicability of axial dispersion model to analyze mass transfer measurements in bubble columns, AIChE Journal, 29 (1983) 915-22.

[22] H. Dhaouadi, S. Poncin, J.M. Hornut, N. Midoux, Gas-liquid mass transfer in bubble column reactor: Analytical solution and experimental confirmation, Chemical Engineering and Processing: Process Intensification, 47 (2008) 548-56.

[23] H. Kojima, J. Sawai, H. Suzuki, Effect of Pressure on Volumetric Mass Transfer Coefficient and Gas Holdup in Bubble Column, Chemical Engineering Science, 52 (1997) 4111-16.

[24] R. Lau, W. Peng, L.G. Velazquez-Vargas, G.Q. Yang, L.-S. Fan, Gas-Liquid Mass Transfer in High-Pressure Bubble Columns, Industrial \& Engineering Chemistry Research, 43 (2004) $1302-11$.

[25] H.M. Letzel, J.C. Schouten, R. Krishna, C.M. van den Bleek, Gas Holdup and Mass Transfer in Bubble Column Reactors Operated at Elevated Pressure, Chemical Engineering Science, 54 (1999) 2237-46.

[26] W.T. Tang, L.-S. Fan, Gas-Liquid Mass Transfer in a Three-Phase Fluidized Bed Containing Low Density Particles, Industrial \& Engineering Chemistry Research, 29 (1990) 128-33.

[27] K. Terasaka, D. Hullmann, A. Schumpe, Mass transfer in bubble columns studied with an oxygen optode, Chemical Engineering Science, 53 (1998) 3181-84.

[28] P.M. Wilkinson, H. Haringa, L.L. Van Dierendonck, Mass Transfer and Bubble Size in a Bubble Column under Pressure, Chemical Engineering Science, 49 (1994) 1417-27. 
[29] M.I. Hossain, S.Q. Pang, Q.X. Pang, Y.H. Yang, R. Lau, Study of Liquid Weeping at a Tapered Orifice in a Bubble Column Reactor by a Computer-Aided Image Analysis Algorithm, Industrial \& Engineering Chemistry Research, 49 (2010) 3840-48.

[30] R. Higbie, The rate of absorption of a pure gas into a still liquid during short periods of exposure, Transactions of American Institute of Chemical Engineers, 31 (1935) 365.

[31] I. Dewes, A. Kueksal, A. Schumpe, Gas density effect on mass transfer in three-phase sparged reactors, Chemical Engineering Research and Design, 73 (1995) 697-700.

[32] C.O. Vandu, R. Krishna, Gas holdup and volumetric mass transfer coefficient in a slurry bubble column, Chemical Engineering and Technology, 26 (2003) 779-82.

[33] R.D. Voyer, A.I. Miller, Improved gas-liquid contacting in co-current flow, Canadian Journal of Chemical Engineering, 46 (1968) 335-41.

[34] W. Yang, J. Wang, Y. Jin, Mass transfer characteristics of syngas components in slurry system at industrial conditions, Chemical Engineering and Technology, 24 (2001) 651-57.

[35] R. Lemoine, A. Behkish, B.I. Morsi, Hydrodynamic and mass-transfer characteristics in organic liquid mixtures in a large-scale bubble column reactor for the toluene oxidation process, Industrial \& Engineering Chemistry Research, 43 (2004) 6195.

[36] P. Mena, A. Ferreira, J.A. Teixeira, F. Rocha, Effect of some solid properties on gas-liquid mass transfer in a bubble column, Chemical Engineering and Processing: Process Intensification, 50 (2011) 181-88.

[37] R. Krishna, M.I. Urseanu, J.M. Van Baten, J. Ellenberger, Rise velocity of a swarm of large gas bubbles in liquids, Chemical Engineering Science, 54 (1999) 171. 
[38] C.O. Vandu, K. Koop, R. Krishna, Volumetric mass transfer coefficient in a slurry bubble column operating in the heterogeneous flow regime, Chemical Engineering Science, 59 (2004) $5417-23$. 


\section{Tables}

Table 1. A list of experimental conditions used

\begin{tabular}{|c|c|c|}
\hline Distributor used & L/D used & $\boldsymbol{U}_{\boldsymbol{G}}$ range $(\mathbf{c m} / \mathbf{s})$ \\
\hline Perforated plate & $2,4,5.6,7.2$ & $3.2-10.8$ \\
\hline Porous plate & 4 & $3.2-10.8$ \\
\hline Single nozzle & 4 & $3.2-10.8$ \\
\hline
\end{tabular}

Table 2. Summary of bubble Reynolds numbers and the $k_{L}$ dependence on $U_{G}$

\begin{tabular}{|c|c|c|c|c|}
\hline Source & Liquid used & Gas used & $\mathbf{R e}_{b}$ & $k_{L}$ dependence on $U_{G}$ \\
\hline This work & Tap water & $\mathrm{N}_{2} /$ Air & $1300-18000$ & Independent of $U_{G}$ \\
\hline $\begin{array}{l}\text { Han and Al-Dahhan, } \\
\text { 2007[19] }\end{array}$ & Tap water & $\mathrm{N}_{2} /$ Air & $10-18000$ & $\begin{array}{l}\text { Increases with } U_{G} \text { at low } U_{G} \text { and } \\
\text { approaching constant at high } U_{G}\end{array}$ \\
\hline $\begin{array}{l}\text { Lemoine et al., } \\
2004[35]\end{array}$ & $\begin{array}{l}\text { Toluene and other } \\
\text { organic mixtures }\end{array}$ & $\mathrm{N}_{2} /$ Air & $100-1500$ & Increases with $U_{G}$ \\
\hline Vandu et al., 2004[38] & Paraffin Oil & $\mathrm{N}_{2} /$ Air & $3000-56000$ & Independent of $U_{G}$ \\
\hline Yang et al., 2001[34] & Paraffin Oil & $\mathrm{CO} / \mathrm{H}_{2}$ & $3000-56000$ & Independent of $U_{G}$ \\
\hline $\begin{array}{l}\text { Gopal and Sharma, } \\
1983[12]\end{array}$ & Dithionite & Air & $800-25000$ & Decreases slightly with $U_{G}$ \\
\hline Dewes et al., 1995[31] & Ionic solution & Air & $2500-44000$ & Independent of $U_{G}$ \\
\hline $\begin{array}{l}\text { Voyer and Miller, } \\
1968[33]\end{array}$ & $\mathrm{NaOH} /$ Water & $\mathrm{CO}_{2}$ & $1000-15000$ & Independent of $U_{G}$ \\
\hline
\end{tabular}




\section{Figures}

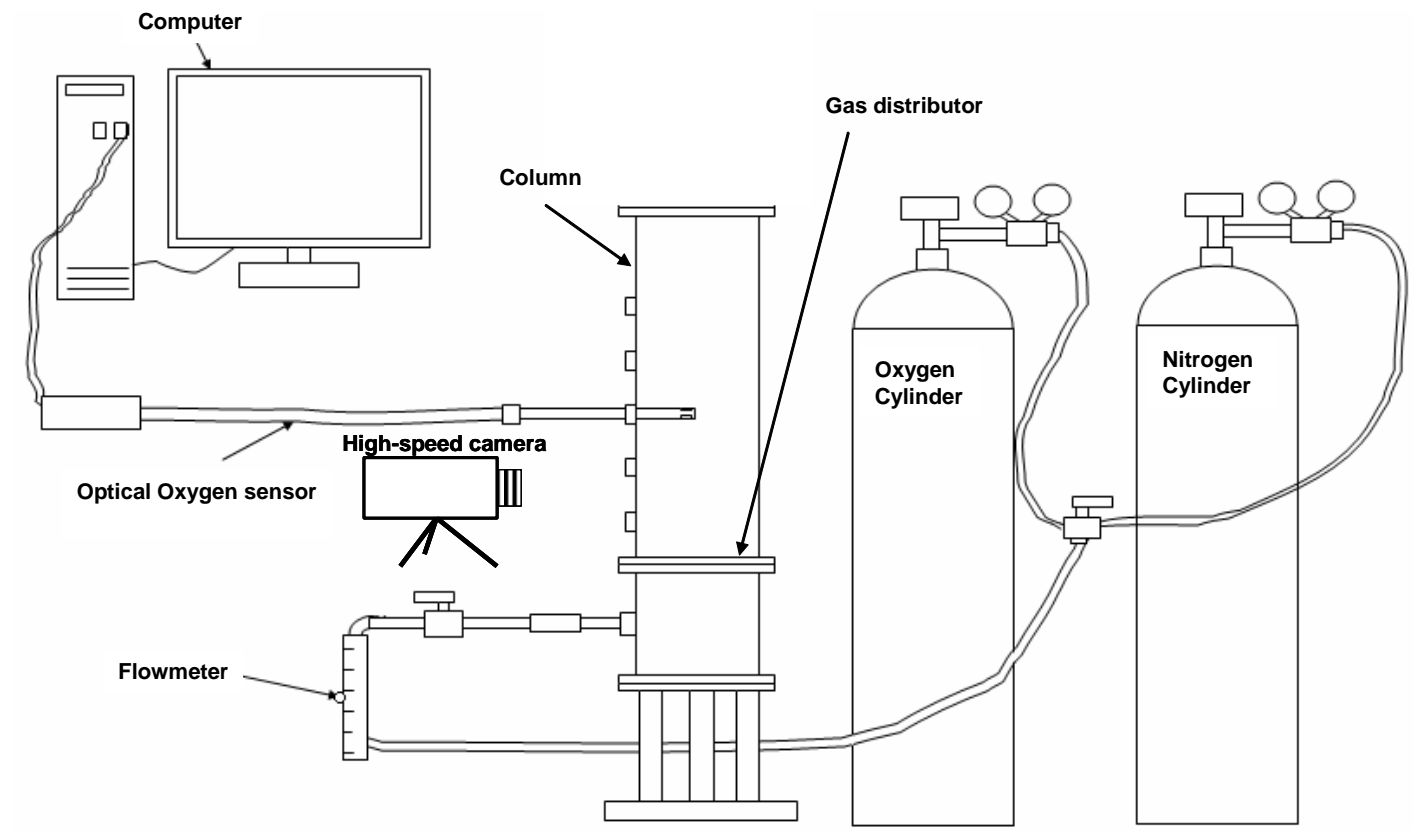

Figure 1. Schematic diagram of the experimental setup. 


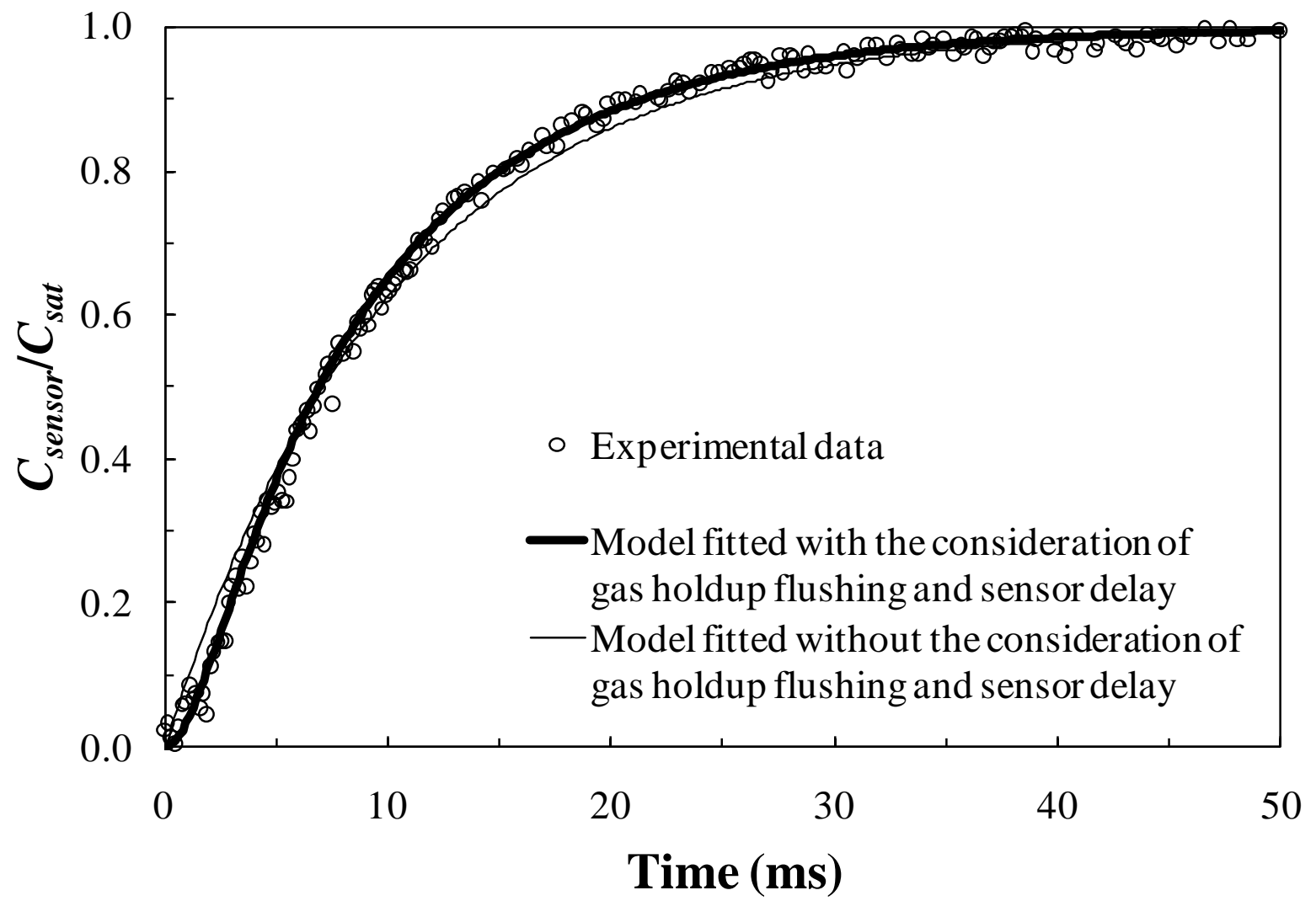

Figure 2. Comparison of model fitting with and without consideration of gas holdup flushing and sensor delay at $U_{G}$ of $8.7 \mathrm{~cm} / \mathrm{s}, \mathrm{L} / \mathrm{D}$ of 7.2 with a perforated plate distributor. 


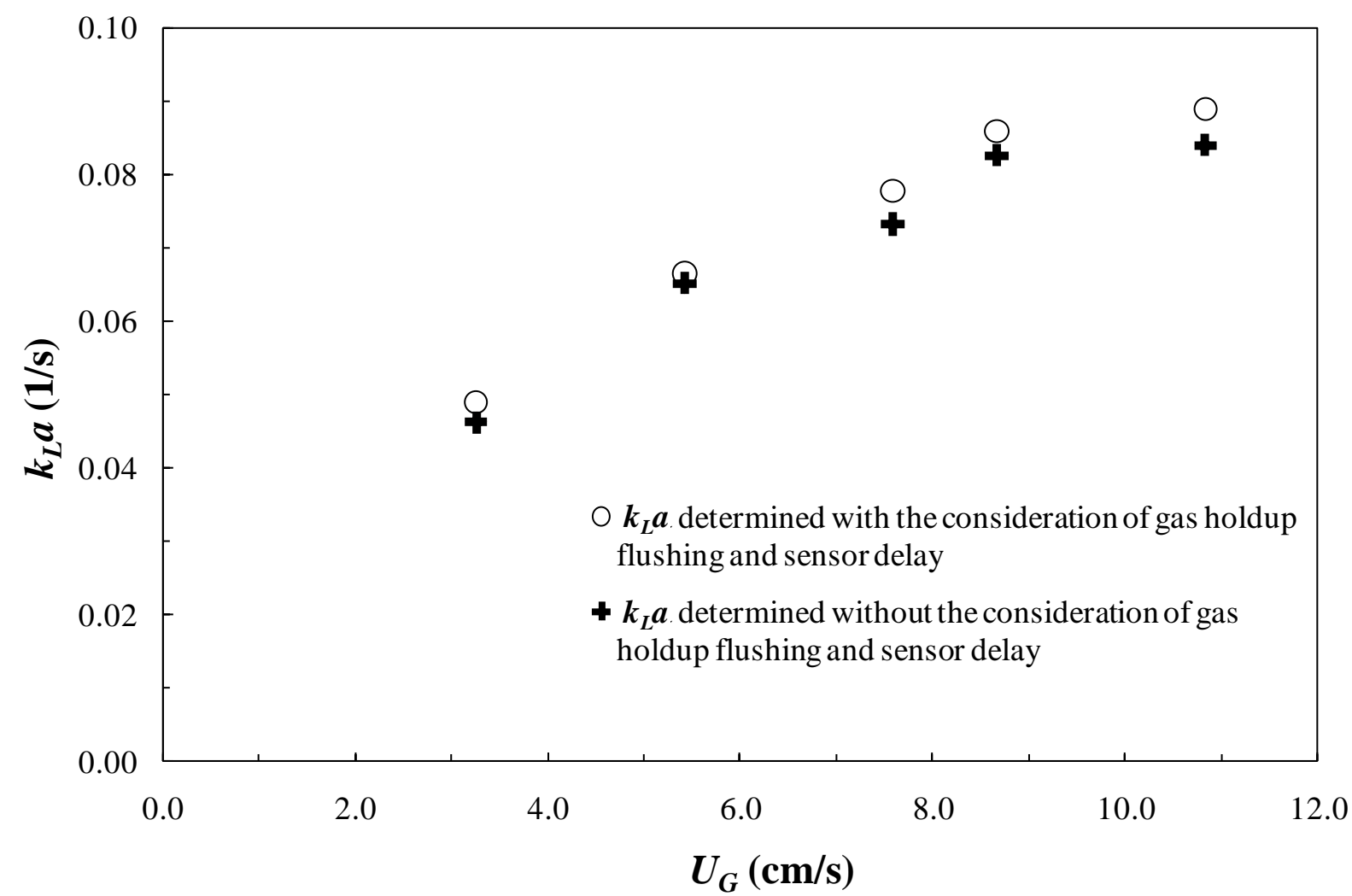

Figure 3. Comparison of $k_{L} a$ determined with and without consideration of gas holdup flushing and sensor delay at $\mathrm{L} / \mathrm{D}$ of 4 with a perforated plate distributor. 


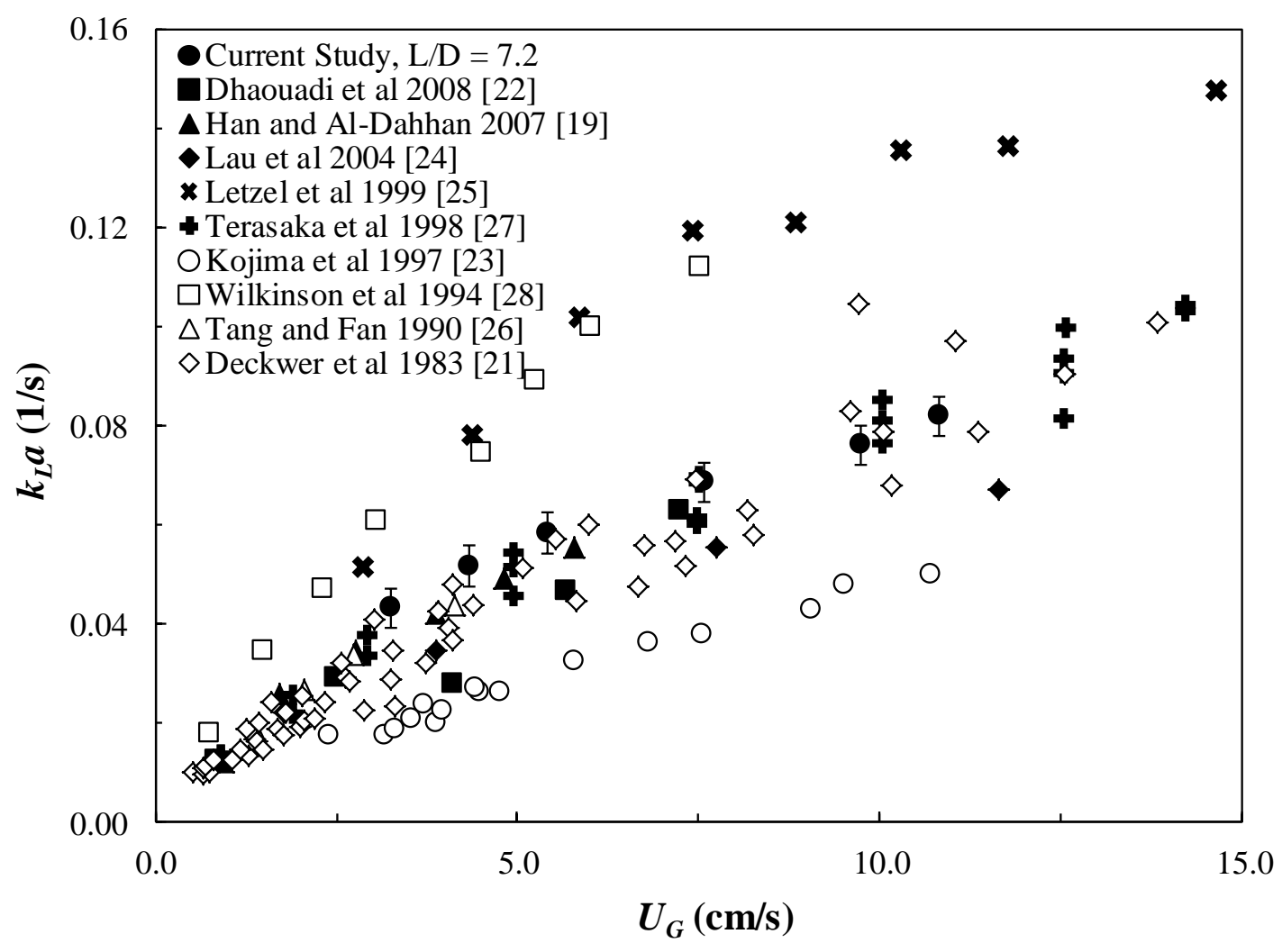

(a)

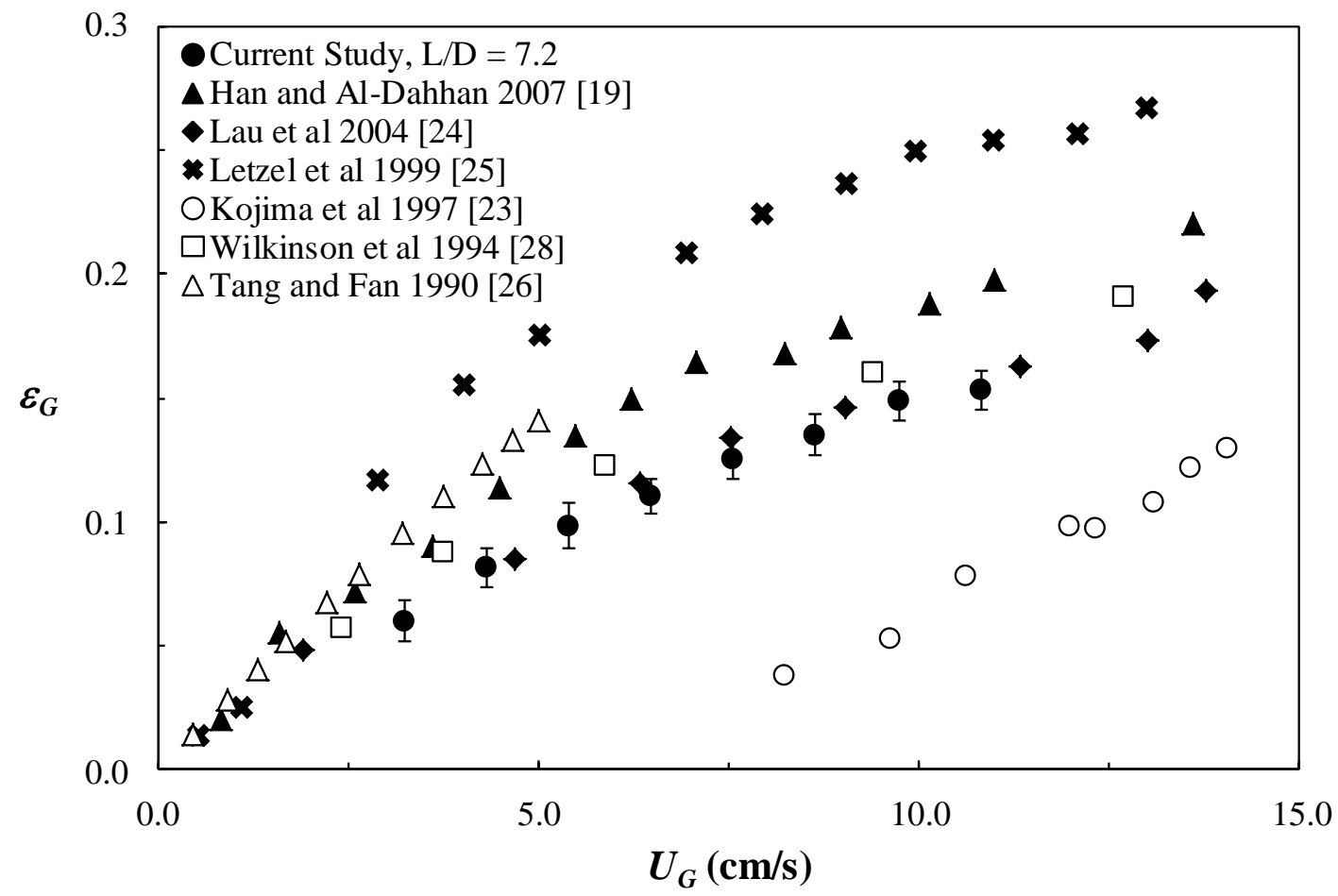

(b)

Figure 4. Comparison to literature data (a) $k_{L} a$, (b) $\varepsilon_{G}$ 


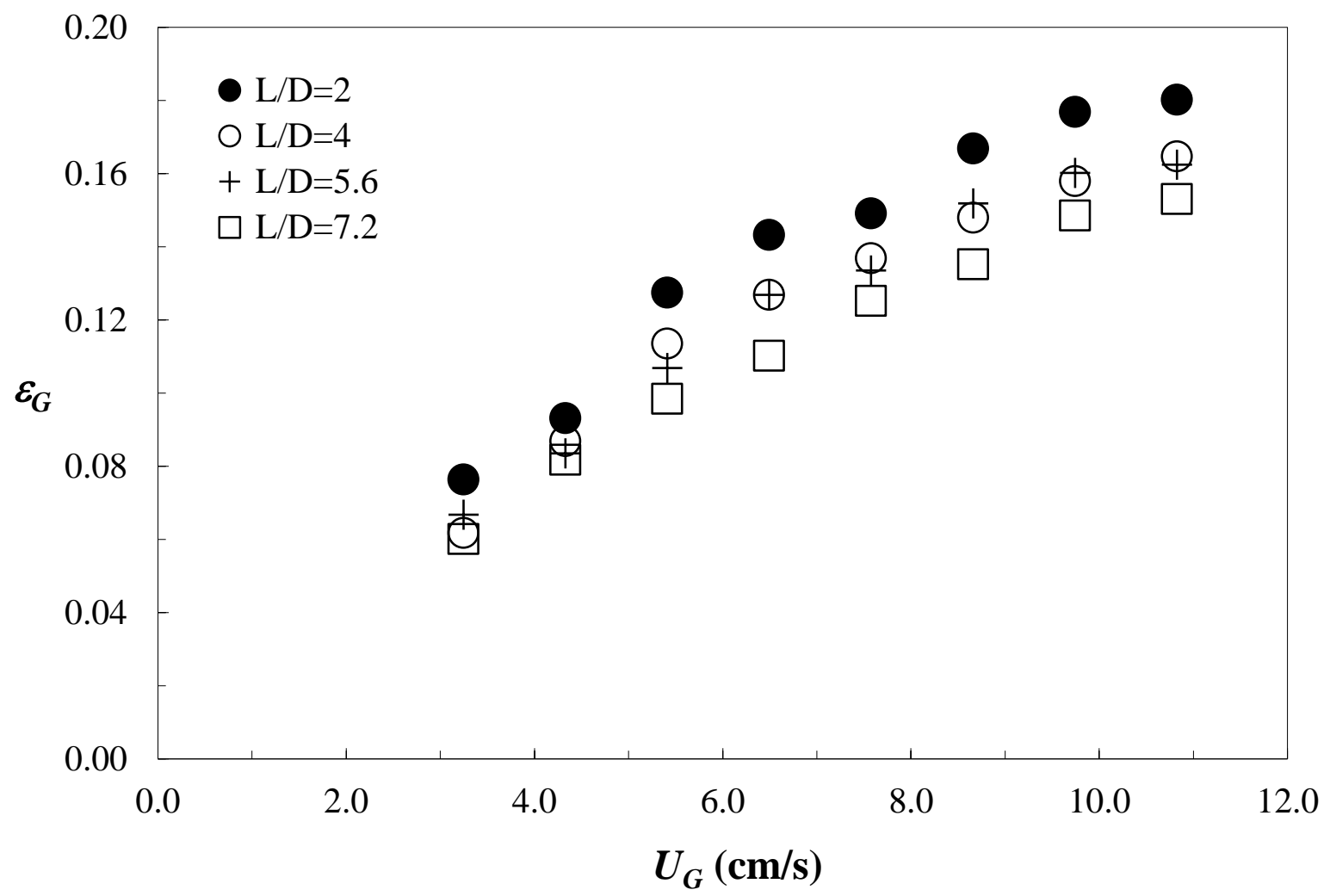

Figure 5. Effect of static liquid height to the gas holdup with a perforated plate distributor. 


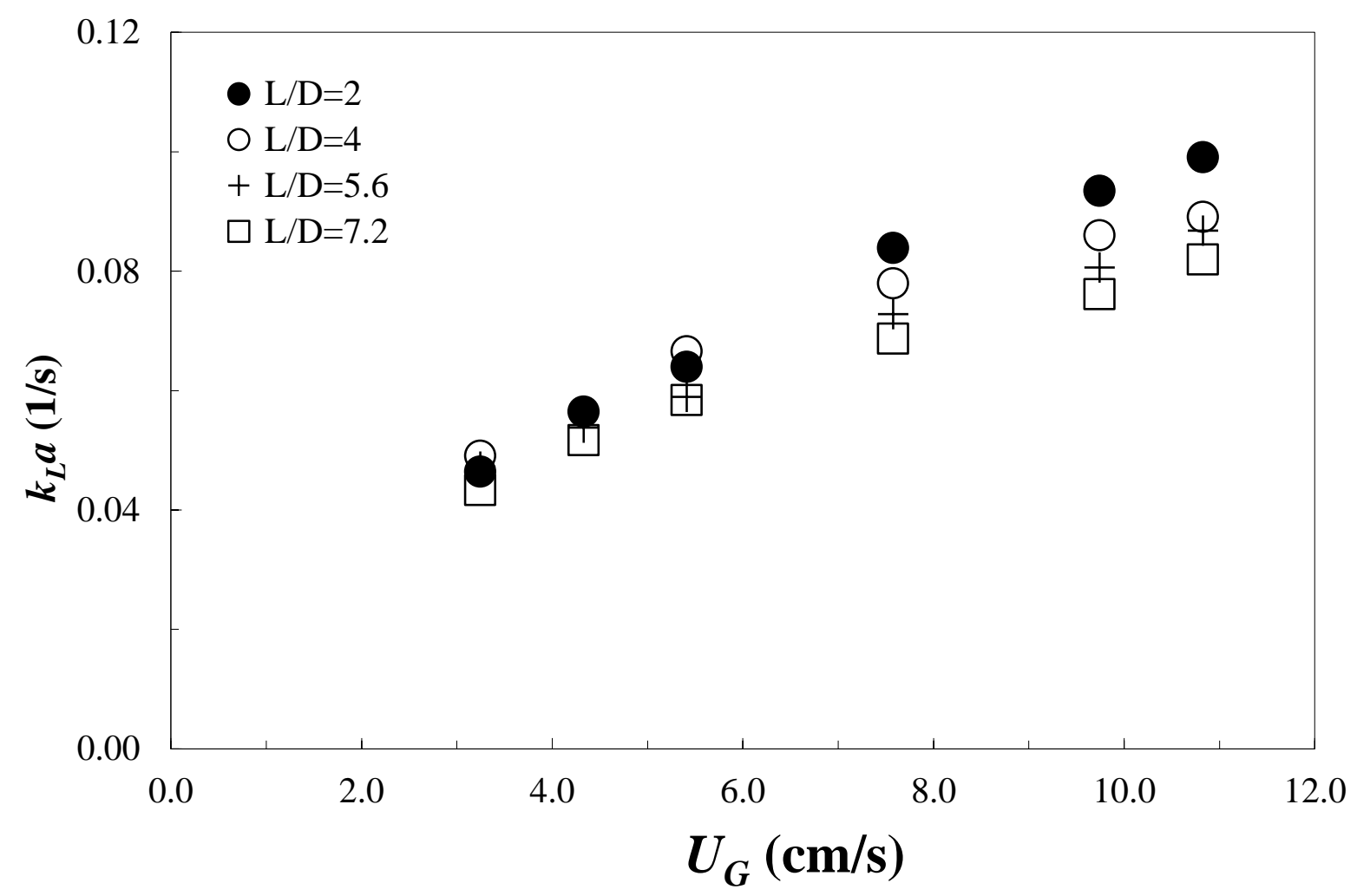

Figure 6. Effect of static liquid height to the volumetric mass transfer coefficient with a perforated plate distributor. 


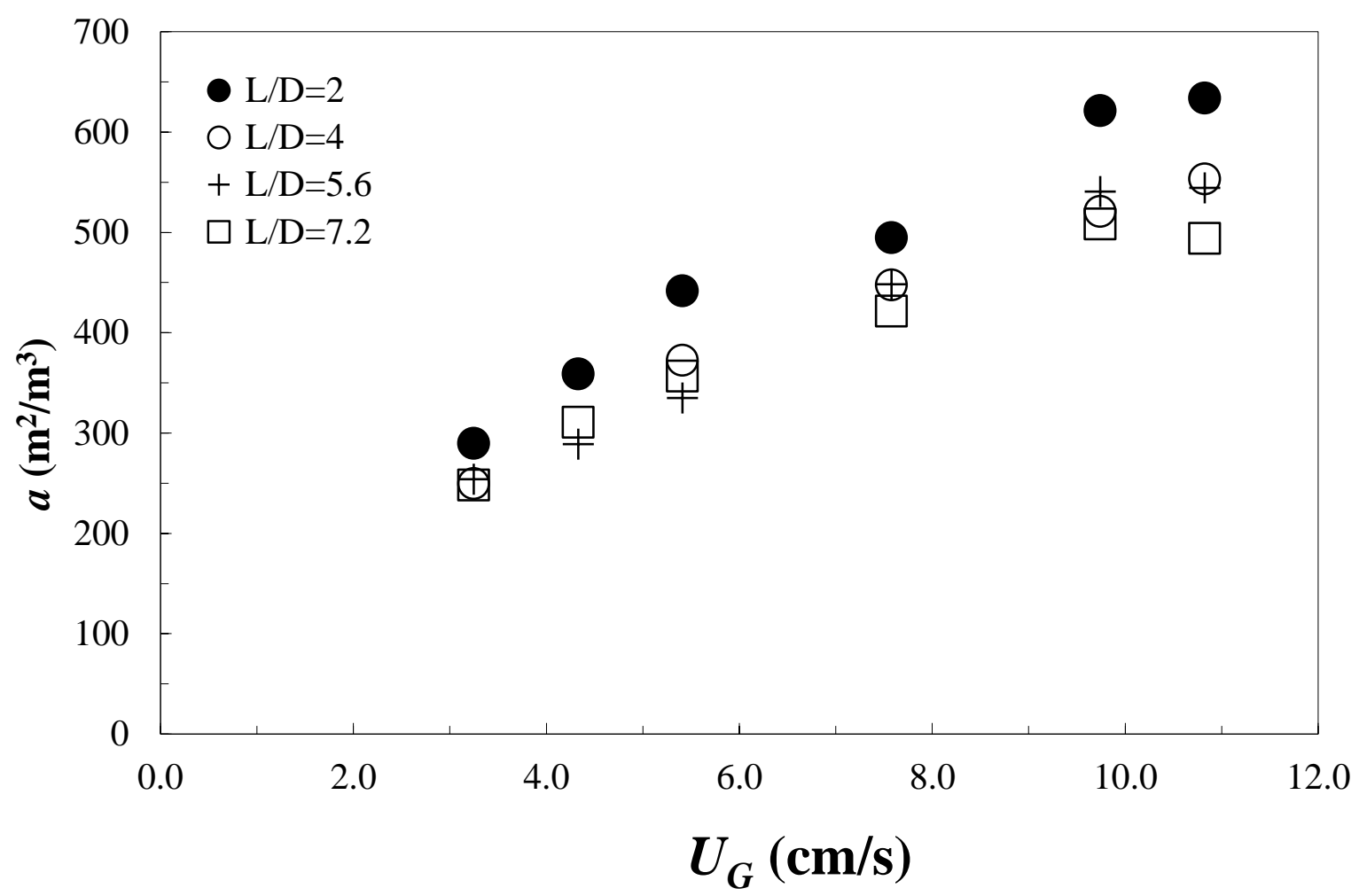

Figure 7. Effect static liquid height on the interfacial mass transfer area with a perforated plate distributor. 


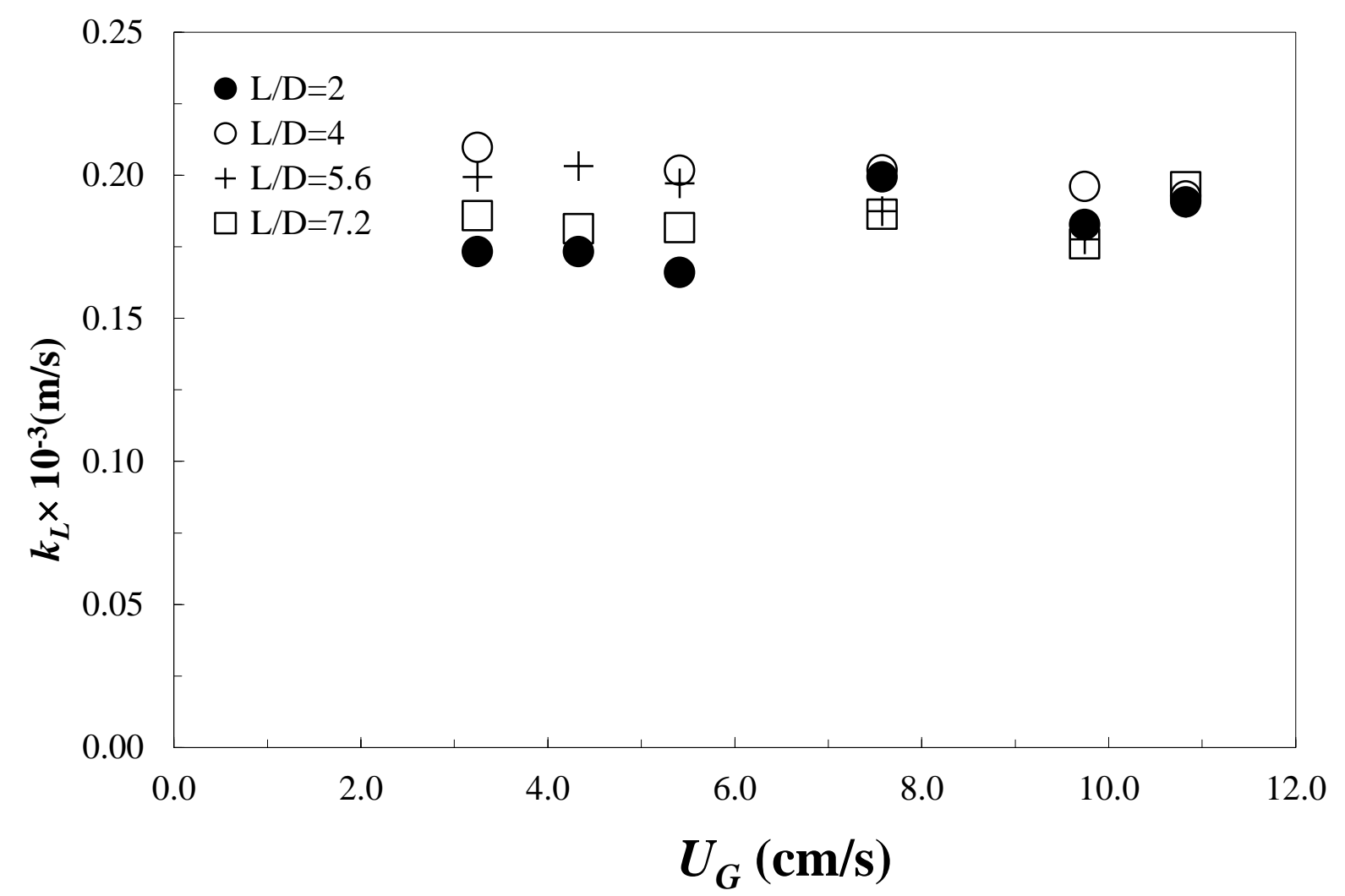

Figure 8. Effect of static liquid height on the liquid-side mass transfer coefficient with a perforated plate distributor. 


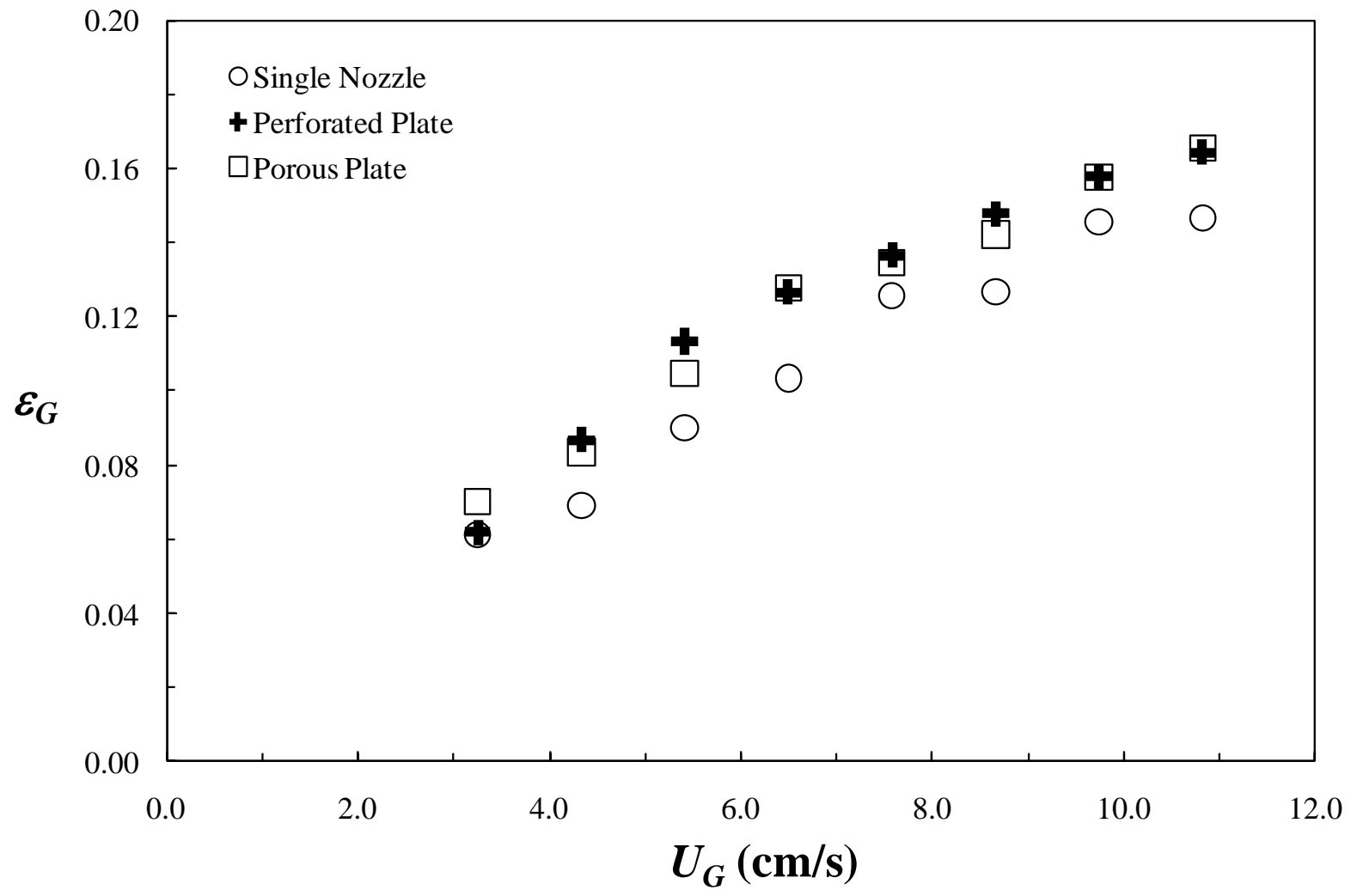

Figure 9. Effect of gas distributor on the gas holdup at L/D of 4. 


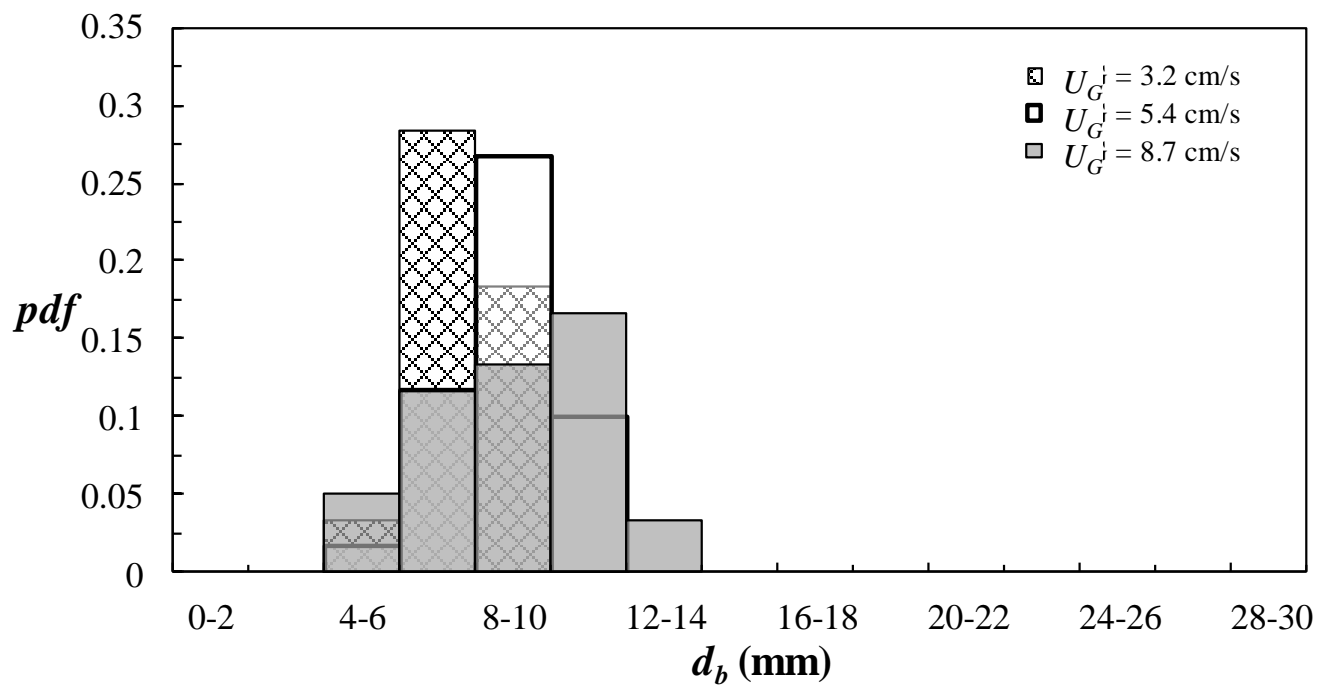

(a)

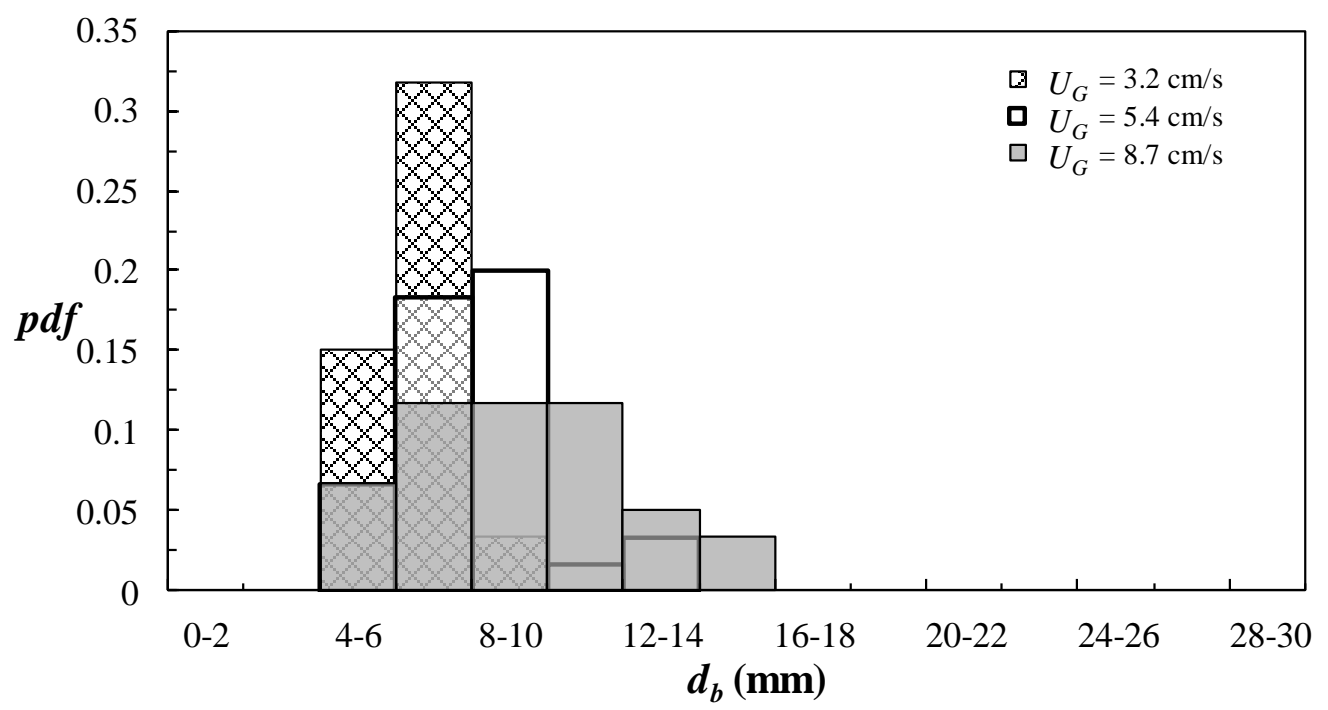

(b) 


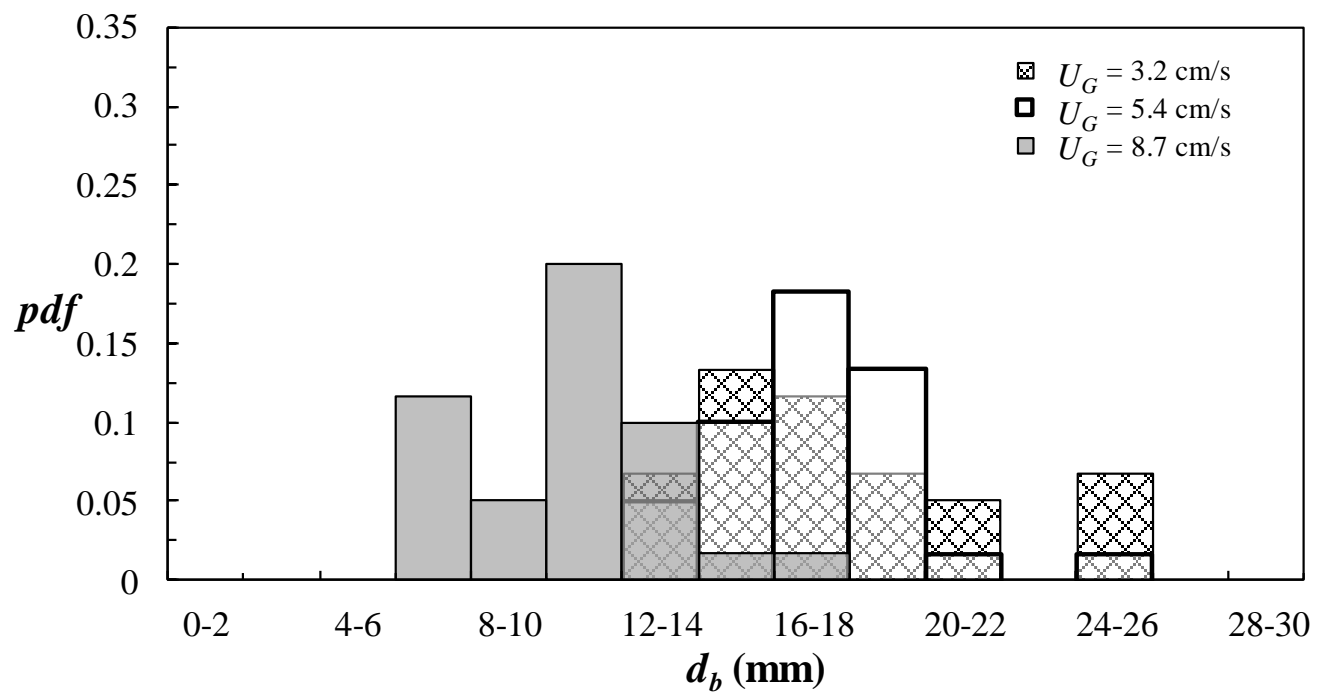

(c)

Figure 10. Bubble size distributions at L/D of 4 (a) perforated plate distributor; (b) porous plate distributor; (c) single nozzle distributor 


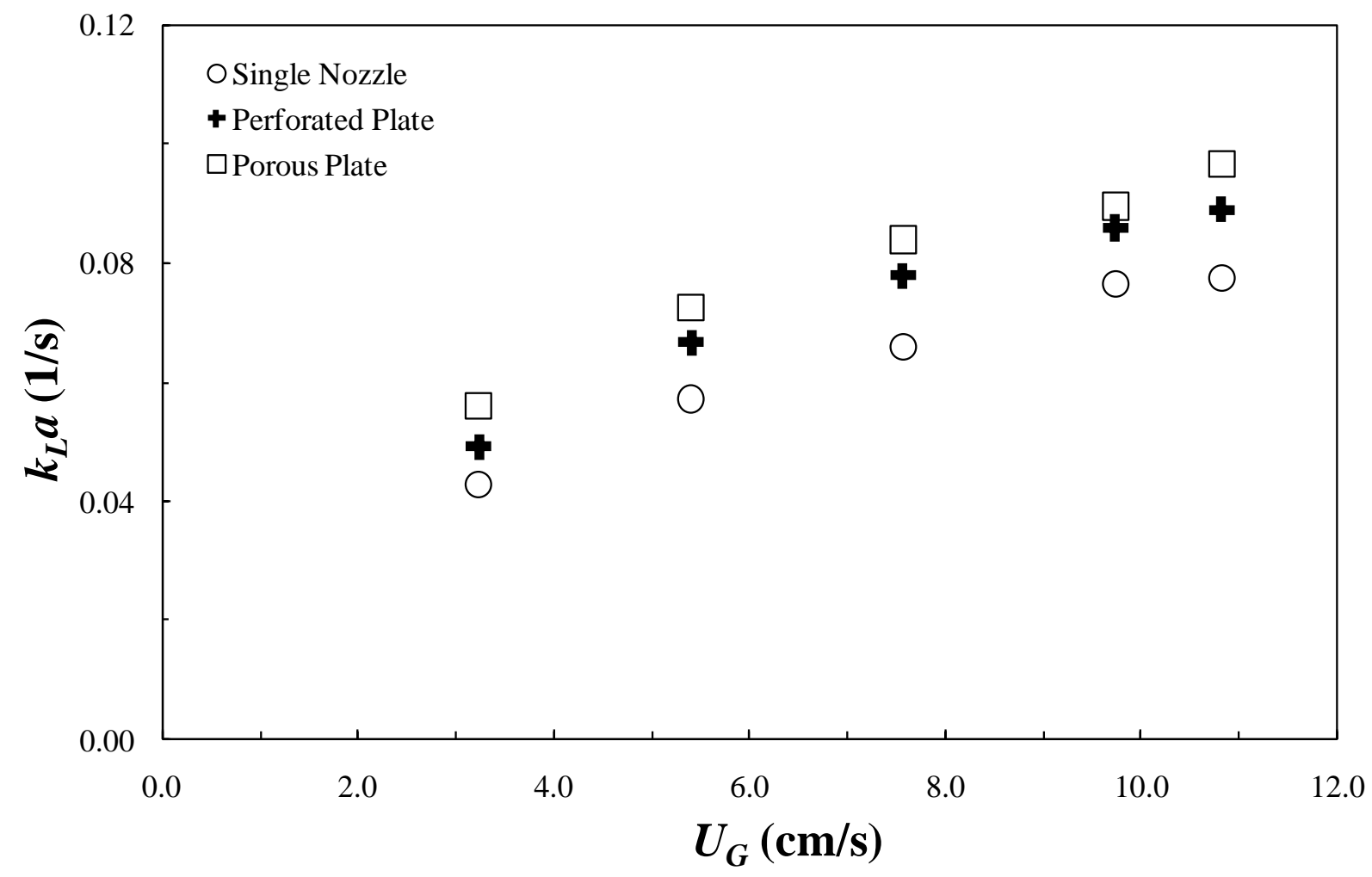

Figure 11. Effect of gas distributor on the volumetric mass transfer coefficient at L/D of 4 . 


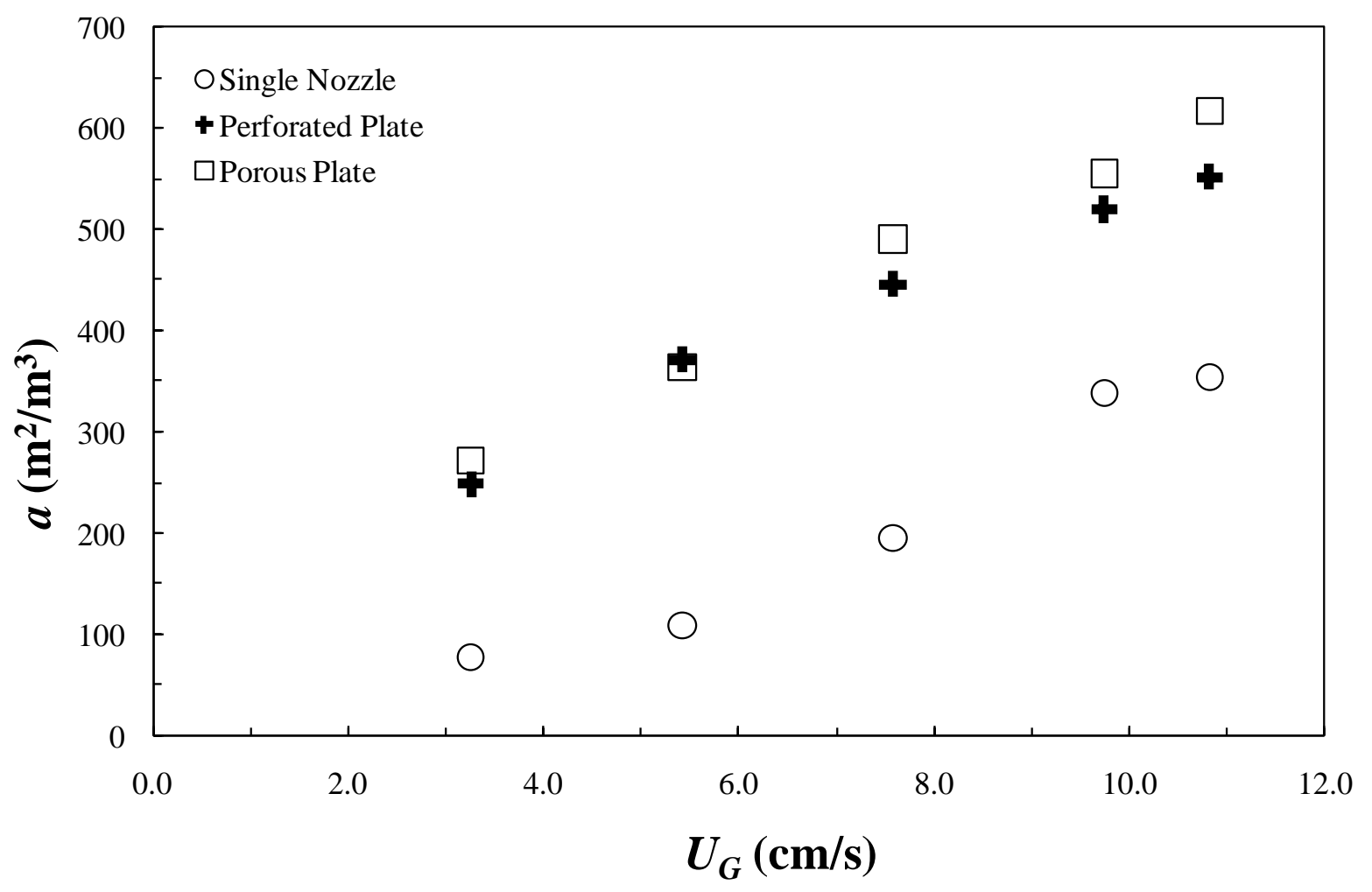

Figure 12. Effect of gas distributor on the interfacial mass transfer area at L/D of 4 . 


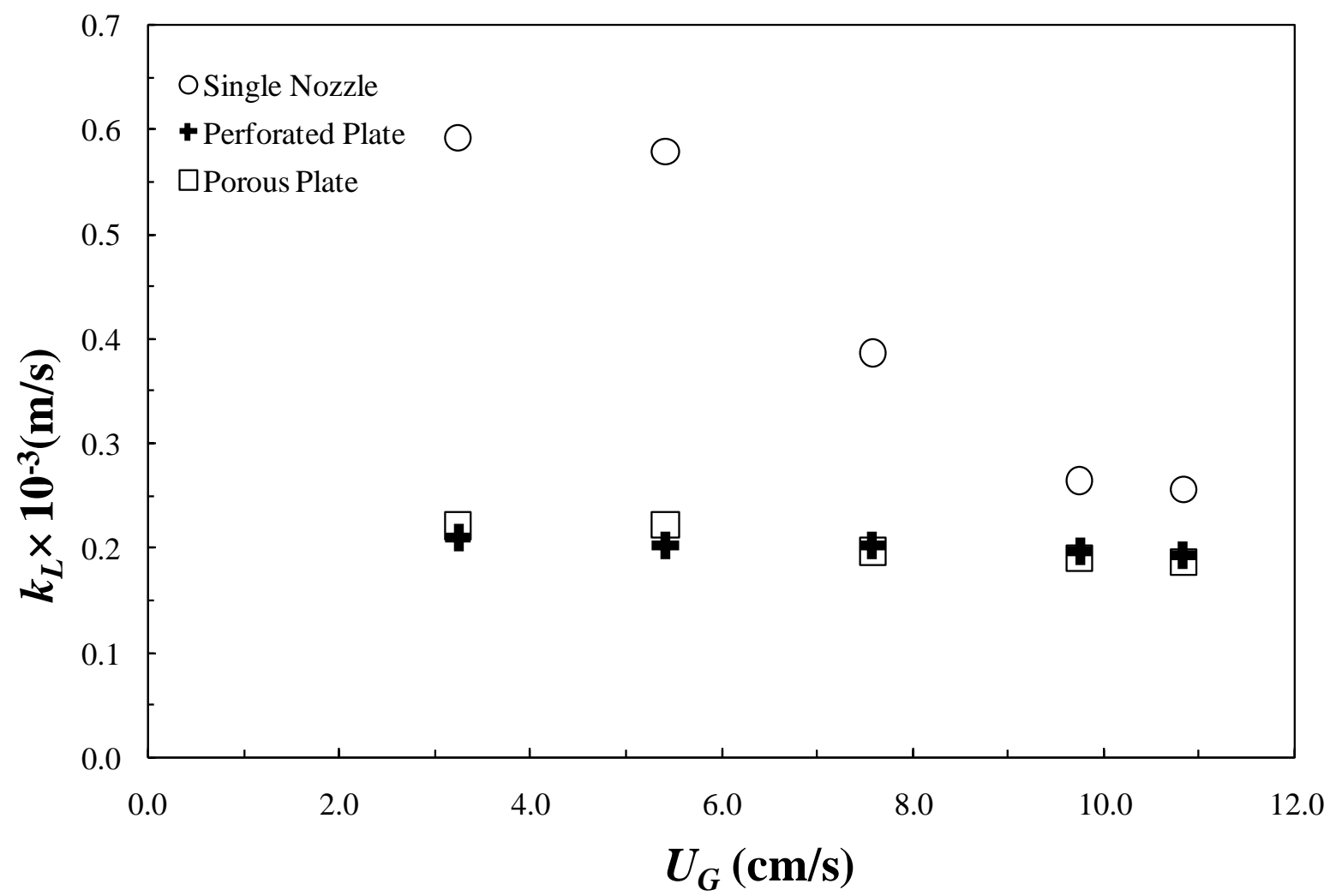

Figure 13. Effect of gas distributor on the liquid-side mass transfer coefficient at L/D of 4 . 